Oriol, Carme; Pere NAVARro; Mònica SAles (2OIO): Literatura oral a Faió, Favara, Maella i Nonasp. Pròleg d'Artur Quintana i Font. Lo Trill I3. Alcanyís-Torredarques: Associació Cultural del Matarranya / Institución Fernando el Católico / Comarca del Baix Aragó-Casp, 273 p. amb fotografies i CD.

\title{
Literatura oral a Faió, Favara, Maella i Nonasp
}

M. D. GIMENO PUYOL

Universitat Rovira i Virgili, Tarragona

A partir d'una iniciativa llunyana i truncada de la comarca del Baix Aragó-Casp, l'Associació Cultural del Matarranya (Ascuma) edita el darrer número de la col-lecció Lo Trill, un important recull de la literatura oral dels pobles catalanoparlants del Baix Matarranya sorgit del formidable i exhaustiu treball de camp de Mònica Sales, professora i investigadora del Departament de Filologia Catalana de la Universitat Rovira i Virgili. El resultat és un treball en equip, coordinat amb mà ferma per Carme Oriol, catedràtica d'Etnopoètica, que també s'ha ocupat de presentar els aspectes literaris dels materials recollits, mentre Pere Navarro, professor de Dialectologia i especialista en els parlars del Matarranya, ha revisat i caracteritzat la part lingüística. D'aquesta manera, l'Ascuma continua la senda de publicacions d'àmbit més extens com Lo Molinar (1995) i Bllat colrat! (1997), ${ }^{\mathrm{I}}$ amb les quals va iniciar la important tasca de recuperació del patrimoni oral de la Franja catalanoparlant d'Aragó, que van ser continuades amb altres recopilacions d'un sol informant, una sola localitat o comarca, segons destaca al seu pròleg el Dr. Artur Quintana, un dels pioners en la recuperació i estudi del gènere a la zona.

Articulada en dos parts, la primera és una introducció, clara i didàctica, on es caracteritzen primer els gèneres literaris recollits i després els trets lingüístics propis de cada poble, amb l'ajut de quadres sinòptics i dos mapes lingüístics — general i comarcal—; a continuació va l'explicació del procediment de recollida dels materials. La recopilació ocupa la segona part, i s'organitza en rondalles, contarelles, llegendes, tradicions, relats d'experiències, acudits, fórmules diverses i cançons i cantarelles per a diferents ocasions i temàtiques. Tot va il.lustrat amb una selecció de fotos dels diversos pobles i un majestuós Matarranya a la portada. Completen el recull la bibliografia especialitzada, l'índex de tipus rondallístics, la identificació al final dels vint-i-cinc informants i un CD amb textos contats per alguns d'ells.

I. QUINTANA, Artur (1995): Lo Molinar. Literatura popular catalana al Matarranya i Mequinensa. 3 vol. Calaceit: Instituto de Estudios Turolenses / Associació Cultural del Matarranya; QUINTANA, Artur (1997): Bllat Colrat! Literatura popular catalana del Baix Cinca, la Llitera i la Ribagorça. 3 vol. Calaceit: Instituto de Estudios Altoaragonenses / Institut d'Estudis del Baix Cinca / Institut d'Estudis Ilerdencs / Diputació General d'Aragó.

Estudis de Literatura Oral Popular, núm. I, 20I2, I98-I99

ISSN: 20I4-7996 | http://revistes.publicacionsurv.cat/index.php/elop 
Es tracta d'una mostra molt significativa d'una societat tradicional on hi havia bruixes, animals que parlaven, contes meravellosos, llegendes de castells o miracles de sants, i també, més arrelades a la terra, explicacions dels renoms familiars, de la peculiar manera de parlar dels altres, de vivències quotidianes, de mostres d'enginy o de successos que sobrepassaven la rutina diària. Estan presents el sentit de l'humor, amb les viles veïnes com objecte de burla habitual; la imaginació festiva d'endevinalles, refranys i fórmules rimades, i els cicles vitals amb els seus treballs, els jocs i les festes. Així, el conjunt retrata un món quasi desaparegut i la seua gent, que contava i cantava allò que vivia amb multitud de matisos i tons: sàvia, vitalista, divertida, irònica o satírica.

Com que els materials s'organitzen segons els subgèneres respectius i no segons localitats, es poden apreciar les coincidències i variacions temàtiques d'un mateix motiu, ja que de cada un dels 507 textos inventariats s'identifica l'informant que l'ha subministrat i el seu poble de procedència. Així mateix, s'indiquen els textos que estan inclosos dins dels catàlegs rondallístics, sobretot l'internacional ATU (Aarne-ThompsonUther), ${ }^{2}$ però també algunes altres catalogacions, i es documenten i comenten breument les diverses versions recollides d'un mateix argument. Aquesta coincidència amb tipus rondallístics presents en altres àmbits geogràfics constitueix una petita part del total, cosa que, d'una banda, resulta suficient per demostrar que la literatura oral de la zona participava dels mateixos motius de la literatura popular universal i, de l'altra, que era molt variat i productiu l'enginy dels autors anònims de relats inventats o basats en fets reals. Com que els textos són una transcripció fidel dels relats recopilats, les seues qualitats literàries depenen, lògicament, de les habilitats narratives dels respectius informants.

El criteri lingüístic adoptat per a la transcripció respecta de manera rigorosa els trets propis de cada una de les quatre viles frontereres, i si això pot constituir una dificultat per a lectors habituats a un català estàndard, també fa del recull una rica mostra que permet comprovar les diferències dialectals entre localitats tan pròximes, molt ben caracteritzades per Navarro a l'estudi preliminar. Segons és habitual en zones sotmeses a la influència d'altres llengües, als textos es troben mots o fragments aïllats en castellà, circumstància que en el cas de la Franja no ha interferit gaire en la llengua catalana rica i pura, plena de matisos que s'ha conservat fins fa ben poc. El territori, marcat encara ara per la diglòssia social i la desídia oficial, pertany a l'àmbit lingüístic i cultural català des dels seus orígens, com revela l'excel-lent recull editat, mostra de l'única literatura -l'oral, popular i anònima - que ha tingut durant segles.

2. UTHER, Hans-Jörg [ATU] (2004). The Types of International Folktales. A Classification and Bibliography Based on the System of Antti Aarne and Stith Thompson. 3 vols. Folklore Fellows' Communications 284-286. Helsinki: Suomalainen Tiedeakatemia. 